\title{
Characterization of the Socioeconomic Inequity Attributable to Smoking
}

\section{Gonzalez ES and Hernandez FF*}

Faculty on Medical Science, University of Medical Science of Havana, Cuba

*Corresponding author: Fe Fernandez Hernandez, Faculty on Medical Science, University of Medical Science of Havana, Cuba, Email: fefh@infomed.sld.cu

\section{Research Article}

Volume 3 Issue 4

Received Date: July 17, 2020

Published Date: August 13, 2020

DOI: $10.23880 /$ jqhe-16000174

\section{Abstract}

Background: The socioeconomic inequity attributable to smoking is a social untouchable cost. It has several forms to impact over the economy and the society in general. At same time, each impact form determines a form of socioeconomic inequity attributable to smoking. Each impact form has associated a particular social cost and particularly fiscal which relevancy will depend from the impact magnitude.

Objective: To characterize the socioeconomic inequity attributable to smoking.

Material and Methods: Was maddening an analytic research about the socioeconomic inequity attributable to smoking. The theatrical methods utilized were the comparative, the inductive-deductive and the analysis and synthesis. As empiric method was utilized the bibliographic research.

Results: The socioeconomic inequity attributable to smoking is given by the social costs attributable to smoking. The main costs are determined by the cost over the Public Health and the costs because of the labor productivity lose attributable to smoking.

Conclusion: Smoking is a risk factor with several social and economic impacts. Each form to impact over the morbidity and the mortality carries to a particular form of socioeconomic inequity. This condition determines the multi-dimensional research from smoking for a better control over this risk factor.

Keywords: Smoking; Inequity; Socioeconomic

\section{Introduction}

Smoking carries to several disequilibrium as socioeconomic inequity cause. These disequilibrium are given mainly by the increasing spends attributable to smoking [1].

As socioeconomic risk factor, smoking is close related with poorness and human development. WHO has appointed the close relation between human develop and tobacco consumption showing that the higher consumptions are in developing countries [2].

These arguments are showing the importance of the smoking economic control in developing countries. In fact, one of the more significant socioeconomic inequity form attributable to smoking is given by the labor productivity loses attributable to this risk factor $[3,4]$.

Smoking carries to redistributions to afford the socioeconomic consequences from it. The real available economic resources determine the capacity to afford the whole smoking consequences. If economic resources are insufficient may appear serious disturbs agreeing to the magnitude of the difference $[5,6]$.

Smoking carries to increase the morbidity and mortality by several illnesses. These consequences may increase the 
demand of social security services and reduce effectively the life expectancy and labor productivity too. Each one of these social disturbs carries to a particular form of socioeconomic inequity attributable to smoking. That's why each inequity attributable to smoking form's may be explained by a related smoking social cost [7-9].

Asrisk factor smoking is very complex. The socioeconomic inequity attributable to smoking constitutes an untouchable social cost attributable to this risk factor. It has several forms to impact over the society and the economy at same time. Each impact form has associated a social cost agreeing to the impact magnitude. Then, the priority in the smoking control should be measured by an instrument to measure the whole socioeconomic inequity attributable to smoking [10].

These arguments are showing the need to characterize the socioeconomic inequity attributable to smoking. Then, the main objective of this research is to characterize the socioeconomic inequity attributable to smoking.

\section{Material and Methods}

It made an analytic research about the socioeconomic inequity attributable to smoking. The theoretical methods utilized were the comparative, the inductive-deductive and the analysis and synthesis. As empiric method was utilized the bibliographic research.

\section{Results}

\section{Tobacco Consumption as Addiction Cause}

A growing in the tobacco consumption intensity carries to higher tobacco addiction too. Consequently will increase the health services demand's attributable to smoking and the reserve price from the smoker and the satiety point will be in longer position too. By other side the labor productivity lose attributable to smoking will increase agreeing to the intensity tobacco consumption and the smokers workers number [11]. Because of all problems from the smoking, several countries had taken strong measures to reduce the tobacco consumption. These actions had demonstrated the useful from effective public policies in the smoking control $[11,12]$.

The good result from these policies was in the knowledge from the smoking social cost. That's why while more precise are the estimating ways more trustable will be the adopted policy for the smoking control [13].

Because of the general knowledge from tobacco as ordinaries and necessaries goods it had checked the effectiveness from the fiscal policy in the smoking control.
Usually the tobacco demand function is very inelastic and more inelastic than the supply tobacco function. As consequence, the useful of expansive tributaries policies is reduced because of the lower reduction in tobacco consumption agreeing to the tobacco consumption intensity $[14,15]$.

Smoking is close related with no-transmissible illness. The treatment from these illnesses usually is very long at time and expensive too. Also, the growing in the tobacco consumption carries to increase the tobacco addiction and the morbidity attributable to smoking and the economic burden attributable to smoking too [16-19].

Because of the main characteristic smoking as risk factor is classified as conductible, modifiable, accumulative and socioeconomic too. Because of these characteristic the detailed knowledge from smoking constitute a main base to apply efficient policies for the smoking control $[20,21]$.

\section{The Socioeconomic Inequity Because of Smoking}

The socioeconomic inequity because of smoking may be absolute or relative agreeing to the reversibility from smoking impact at less in short time. The absolute is related to the irreversible consequences from smoking while the relative is related with reversible consequences both at least in short time.

The relative socioeconomic inequity by morbidity attributable to smoking is given by the whole health costs attributable to smoking. In this way the smoking economic burden is main measurer of this inequity form.

The relative socioeconomic inequity attributable to smoking by morbidity don't means that clients be excluded from the health services market. This inequity form is referred to how much more expensive is the health service because of smoking front of the no existence of this risk factor.

The absolute socioeconomic inequity by morbidity attributable to smoking is determined by the redistribution effect in the health services market because of smoking. The continue tobacco consumption carries to increase the morbidity attributable to smoking and the smoking economic burden too. The continuing increase from the health services demand because of smoking carries to make more expensive the health services. As consequence a significant clients number most leave from the health services market agreeing to the smoking impact over the health services market.

The absolute socioeconomic inequity attributable to 
smoking by mortality is referred to how much lose the whole society because of the early death attributable to smoking. Given that mortality is irreversible the relative socioeconomic inequity attributable to smoking by mortality don't exists [22-24].

The absolute socioeconomic inequity attributable to smoking occurs when health services clients must leave the health market and then can't access to these services. This inequity form it show by mortality and morbidity too.

\section{The Absolute Socioeconomic Inequity Attributable to Smoking by Mortality}

The absolute socioeconomic inequity attributable to smoking by mortality has peculiar characteristic. In this case it is important to appointment that the over mortality because of smoking is determinants cause of this inequity form. The existence of this over mortality type is determining a social inequity given by the differences in life expectation between smokers and no-smokers people. Nevertheless, the absolute socioeconomic inequity attributable to smoking by mortality occurs if earlier death attributable to smoking represents a socioeconomic cost. Then, absolute socioeconomic inequity attributable to smoking by mortality is determined by the absolute labor productivity lose attributable to smoking [25].

A peculiar form to measure this inequity form should be by accounting all opportunities costs attributable to smoking by earlier death attributable to smoking before retire age. For example, in Cuba 2011 the over mortality attributable to smoking in men was around 18.4 years. This determined an over mortality of 3.22 years respect to the retire age. As consequence, the Cuban economy didn't obtained close to 295 million of pesos [26].

\section{The Absolute Socioeconomic Inequity Attributable to Smoking by Morbidity}

The absolute socioeconomic inequity attributable to smoking by morbidity is given by forms covering the health services. These services may be covered by fiscal resources or privates resources. In this case only is considered as private services which are covered by insurance rate [27].

The health services demand attributable to smoking are determined by tobacco consumption intensity and the smoker number. That's why smoking induces to increase the health services demand agreeing with tobacco consumption intensity and the smoker number [28].

Increasing some of these variables health services demand should increase too and clients from the Public Health market should experiment an increasing from the health insurance rate. Clients who can't afford the new price agree with the particular service demanded should leave from the Public Health market. Thus is manifested the absolute socioeconomic inequity attributable to smoking by morbidity when the health services are covered by privates resources [29].

When the health services demand is covered by fiscal resources smokers and no-smokers people are demanding these services agree with personal needs. Increasing tobacco consumption intensity and/or the smoker number the health services demand will increase too. The fiscal authorities should decide if are agreeing in cover the increasing demand attributable to smoking. Economic resources are always limited and often will not possible cover the new demand. Consequently not all demanded services should able and a significant client number will haven't access to the demanded services. At same time smokers will increase the frequency demanding the health services agree with the tobacco consumption intensity. That's why no-smoker people should experiment least access to health services because of smoking [30].

\section{Public Resources Vs. Private Resources Affording the Absolute Socioeconomic Inequity Attributable to Smoking}

All goods and services markets are imperfect. The Public Health market too. Given the antagonist relation between privates resources and fiscal resources covering the health services demand because of smoking, to control, reduce and eliminate the absolute socioeconomic inequity attributable to smoking the most important thing isn't how cover the health services demand because of smoking. This discussion doesn't solve the main cause of this inequity form [31].

Smoking is the main cause of the existence of this particular inequity form. That's why to eliminate the absolute socioeconomic inequity attributable to smoking is necessary focus the attention in the reduction of the tobacco consumption intensity as main explicative variable for personal smoker demand of health services because of smoking [32].

By other side smoking is affecting several economic and social sectors at same time. Then, the whole society and not only the Public Health must be protagonist for all strategic controlling and reducing smoking. Independently from who is covering the health services demand attributable to smoking the most important think is have a whole knowledge about smoking consequences and play an active role controlling, reducing and eliminating the absolute socioeconomic inequity attributable to smoking. 
Smoking may be explained by the tobacco consumption intensity and the smoker number. The single variation of some of these variables carries to a variation of smoking impact in a same way. Consequently, the smoking inequity forms will show a variation in the same way that these two main variables $[33,34]$.

Smoking overcharges to no smoker people. By this way it creates a special socioeconomic inequity form attributable to smoking given by the social cost transferred from smokers to no smokers. The main examples are the passive smoker case who are suffering the same morbidity consequences that smokers agreeing to the whole tobacco exposition [35].

In the case of the tobacco consumption intensity this is in dependence of the before tobacco consumption intensity because of the accumulative effect from smoking. This relation is determined by an accelerated growing relation from the morbidity attributable to smoking front of the tobacco consumption intensity.

The socioeconomic inequity attributable to smoking must be analyzed moreover financial costs because of the existence of social cost don't measured by financial costs. This is the case of lose in quality life and the life expectancy reduction. That's why the instrument to measure the socioeconomic smoking inequity must take account this elements for a better measurement from smoking inequity forms [36].

The social costs attributable to smoking will provide a base for an accounting from the touchable smoking social costs. Since a general social perspective these costs may be classified as following:

Direct health costs of smoking: these are the costs that all health institutions must bear for reasons clearly attributed to smoking. In this particular case, it is valid to clarify that not all the health costs of active smokers are attributable to smoking, nor are all the costs of non-smokers alien to smoking. That is, in this context it is necessary to include the institutional health costs clearly attributable to smoking in active smokers and passive smokers, where the concept of disease burden plays an important role in this quantification. An example of this cost would be the part of the health budget clearly attributable to smoking in active and passive smokers [37].

Direct non-sanitary costs of smoking: these are the costs that all non-sanitary institutions must assume for reasons clearly attributed to smoking, which are very closely related to social security, for example the payment of insurance and subsidies for reasons of attributable disease clearly to smoking in active and passive smokers [37].

\section{Indirect Costs Due to Loss of Labor Productivity: Absolute and Relative}

Regarding the individual's state of health, smoking as a risk factor can play an important role due to the adverse effects it has on the individual and collective performance of the workforce as a special commodity that transforms raw materials into a product [38]. That is, smoking is not only a determinant of the health of the individual, but also of their labor productivity demonstrated through their work. These adverse effects are evident in the labor productivity demonstrated by the individual through mortality or morbidity.

The loss of labor productivity due to or attributable to smoking can then be disaggregated, based on the final result, in absolute or relative. The absolute is that which is associated with mortality and, therefore, is irreversible, since it implies the death of the individual at ages and under appropriate faculties for work, according to their characteristics and legislation in force in the study society. The relative is that which is associated with morbidity, does not imply the death of the individual and its fundamental characteristic is the reversibility, that is, the possibility of the individual returning to work.

The absolute loss of labor productivity is conditioned by various factors, social, economic and legal. From the social point of view, it influences the level of acceptance and tolerance that society in general and in particular the labor group demonstrates towards the consumption of cigarettes or tobacco. Also the level of risk perception of smoking, especially by all individuals related to the consumer of cigarettes, whether in their work environment or not.

From an economic point of view, factors directly associated with the market influence, such as the particularities of the demand and supply of these products, which ultimately determine the market equilibrium of these products. Among the particularities of the demand, the individual purchase capacity and the need for consumption induced by the addictive action of cigarette and tobacco consumption can be mentioned. In the case of the offer, the diversity of manufactured tobacco products available in the market and the price of these are important too.

From the legal point of view, there are the regulations of the labor activity in the study society, such as the case of the minimum age for someone to legally work and the minimum age for a worker, according to their circumstances, to retire. A refined quantification of the loss of labor productivity would include the analysis with the amount of the labor force that actually worked during the study period, and the total amount of the production of goods and services generated in 
this period of time, the life expectancy of regular consumers of cigarettes or tobacco and the minimum age required for the individual's retirement.

In this regard, it should be taken into account that using the economically active population would not be an entirely robust indicator, because it includes in its accounting the population that is unemployed and who, without being technically unemployed, does not work, either for reasons beyond Your will or not.

At the same time, the relative loss of labor productivity can be of two fundamental types: due to the worker's physical absence from work or the worker's physical absence from work. The first is given because the worker is absent from work due to smoking (given this absence due to the relationship of smoking and morbidity), although there is no legal document that proves it, for example, a medical certificate for a disease common where smoking is a relevant risk factor.

The second is given because although the worker is physically at work during the day, but part of that time is spent smoking, thus neglecting his work. In the case of the worker's physical absence from work, these absences may be attributable to smoking or not, regardless of whether they are considered justified or not from the labor or legal point of view. In any of the cases, the influence of smoking as a risk factor increases the worker's morbidity due to any of the causes related to smoking as a risk factor and the possibilities of physical absence to the work area would also increase due to this same influence.

Therefore, if the total number of absences associated with the morbidity of smoking was known, whether these are justified or not and the relative weight of smoking in general morbidity, then the part corresponding to the smoking in this loss of labor productivity.

In this case, it should be specifically taken into account that the expense generated by smoking on social security in an individual is independent of the loss of relative labor productivity due to the physical absence from work, although this expense is an indirect social cost that society must assume for the existence of smoking.

The relative loss of labor productivity due to the worker's physical absence from work is a bit more complex, because apparently it does not exist, due to the fact that the worker meets the time of his working day. However, it should be remembered that the fundamental reason for the existence of the loss of labor productivity is given by not using the time to work, for any of the causes. Therefore, the time of the workday that the worker dedicates to smoking, although apparently he is working without leaving his job, implies that he is not paying due attention to the task that he must perform as a worker and that the time he is dedicated to smoking, from the point of view of employment, it is a wasted time, which implies a loss of labor productivity.

\section{Inequity Attributable to Smoking in the Allocation Of Resources}

For the financing of Public Health, it is necessary to allocate economic resources to this socioeconomic sector. Part of these resources are used to address causes of morbidity and/or mortality clearly attributable to smoking, if this risk factor does not exist, this allocation would not be necessary and these resources could be available in favor of social and human development.

This inequality is given by the very existence of smoking that manifests itself in active and passive smokers at the same time, determined by the level of cigarette and tobacco consumption, morbidity and or mortality directly related to smoking as a factor of risk and the effective demand for health services for reasons clearly attributable to smoking, where the active consumption of cigarettes and tobacco constitutes the fundamental explanatory variable of the existence of smoking and the inequality induced by this risk factor [39].

The full existence of smoke-free spaces is capable of nullifying passive smoking in the environment circumscribed to this space and nullifying in its jurisdiction the inequality of smoking due to the non-existence of active consumption of cigarettes and cigars, but it is not a definitive solution, since It is not able to completely eliminate active consumption of cigarettes and tobacco in the entire social environment to which it belongs.

For the reasons previously argued, the global economic burden of smoking is a first-rate measure of the socioeconomic inequality attributable to smoking in the allocation of economic resources for the financing of health services [40].

The economic burden of smoking in Public Health can have extensive or intensive growth. It is extensive if it increases the effective number of smokers and is intensive if it increases the per capita consumption of cigarettes and/or tobacco. As a result of the interaction of both forms of increase, the economic burden attributable to smoking in Public Health may or may not increase depending on the simultaneous behavior of smokers, which demonstrates the behavioral nature of smoking as a risk factor. For these reasons, it may be the case of societies with a marked demographic decline with high levels of per capita consumption of cigarettes 
whose economic burden attributable to smoking in Public Health is higher than other societies where the consumption of these products is more extensive but with less intensity of consumption [41].

However, although this economic burden is null because there is no effective demand for health services clearly attributable to smoking, there is still room for the existence of a small level of consumption that is less than the minimum amount of consumption that determines the existence of demand Effective health services for reasons clearly attributable to smoking as a risk factor. This non-zero level of cigarette and tobacco consumption may be associated even with another form of socioeconomic inequality attributable to smoking, this being the one that occurs as a result of the social redistribution of economic resources due to the existence of the loss of labor productivity attributable to smoking.

\section{Inequity Attributable to Smoking in the Redistribution of Resources}

Indirect costs from a social perspective are given by the general impact of smoking on society without seemingly direct influence. These costs are especially associated with those that society must assume for the loss of labor productivity generated by this risk factor and are linked to the social redistribution of the economic resource caused by this loss of labor productivity. Therefore, smoking is a cause of socioeconomic inequality from the point of view of the redistribution of the economic resources of society.

The loss of labor productivity attributable to smoking, whether relative or absolute, causes the social cost induced by this loss, to be plunged by society in general and socially redistributed between smokers and non-smokers, making the population sector unaffected by this risk factor bears part of the costs that this loss of labor productivity generates, thus creating socioeconomic inequality in the redistribution of economic resources in the study society.

In the case of the relative loss of labor productivity attributable to smoking, labor absenteeism due to this cause implies that socially workers who are not absent from working hours must cover the absence of those affected by the relative loss of labor productivity attributable to smoking and / or stop producing material wealth as a support for the economic development of society. In addition, this same absenteeism can lead to a greater request for a health benefit, which increases the cost levels for relative loss of labor productivity attributable to smoking.

Social redistribution induced by the relative loss of labor productivity attributable to smoking can have a particularly negative impact on the same consumers of cigarettes and tobacco, who, due to absenteeism attributable to smoking, reduce the family income available for non-cigarette consumption and Tobaccos This situation causes poverty levels to increase and these same people get involved in a vicious cycle of smoking, absenteeism and poverty. Otherwise, the absence of cigarette and tobacco consumption would definitely break this vicious circle, although not immediately, but it would eliminate a major cause of socioeconomic poverty and inequality.

On the other hand, the absolute loss of labor productivity attributable to smoking implies an irreversible loss due to the premature death of the smoker. In this case, as in the previous case, the absence of workers who died prematurely due to causes attributable to smoking should be covered and / or cease to produce material wealth that could be reallocated to strategic sectors of the social and human development of the society of study. However, the irreversibility of this cost means that the recovery of the working mass is based on demographic dynamics, which, by its very nature, is not as accelerated as the replacement of the labor force could demand, which makes this Socially speaking, it becomes more persistent over time, as well as the socioeconomic inequality of smoking in the redistribution of economic resources in society.

In both cases, the consumption of cigarettes and tobacco constitutes the root of the existence of the socioeconomic inequality attributable to smoking and it is this same recurrent consumption that determines the persistence of this cause of social inequality. Therefore, to eradicate this type of inequity it is necessary to eliminate the cause that originates it: the active consumption of cigarettes and tobacco. For this, the political will of the government authorities plays a decisive role. The political basis of tobacco control in Cuba is briefly presented below.

\section{Inequity Attributable to Smoking in the Consumption of Health Services}

From the health services, a significant part is to satisfy the health service demand because of smoking. By this way it establishes an inequity based on the morbidity increasing because of smoking. This disparity is directly determined by the tobacco consumption, the morbidity related to smoking and the effective demand o health services because of smoking. That's why the economic burden attributable to smoking is a main rate to measure the social inequity attributable to smoking since the health consumption.

The epidemiologic burden is given by the social relevancy from the morbidity attributable to smoking. It is equivalent to the probability of the morbidity attributable to smoking. 
The smoking economic burden by morbidity is determined by the social relevancy from the health spend because of smoking. It is equivalent to the probability of the health spend because of smoking.

The smoking economic burden is determined by the smoking epidemiologic burden. That's why the smoking economic burden is a single expression from the smoking epidemiologic burden. By them the socioeconomic inequity attributable to smoking is a single form from the social inequity attributable to smoking too [31-33].

\section{Socio-Labor and Socioeconomic Inequity by Labor Productivity Loss Attributable to Smoking}

Labor productivity loss attributable to smoking may be absolute or relative. The absolute is given by the over mortality because of smoking in labor age. The relative is given by the morbidity attributable to smoking and is associated to the labor time loss because of smoking [38].

Relative labor productivity loss may be by touchable or untouchable absence. The touchable absence occurs when the worker smoker is physically absence at workplace because of smoking. By other side the untouchable absence occur when the worker smoker is physically at workplace but use a part from the work time to smoke [38].

Each of these labor productivity losses carry to social costs attributable to smoking. By the same the social inequity attributable to smoking by labor productivity loss will depend from the self-characteristic of each labor productivity loss because of smoking [38].

By general way it may identify two main forms of social inequity by labor productivity loss attributable to smoking: the socio-labor and the socioeconomic. The socio-labor is given by the labor time loss because of smoking. By other side the socioeconomic inequity by labor productivity loss attributable to smoking is given by the whole economic cost attributable to this particular labor productivity loss [42].

\section{Conclusion}

Smoking is a risk factor of several socioeconomic impacts at same time. Each impact form carries to a socioeconomic inequity form. This condition carries to a multi-dimensional research from smoking to explain the socioeconomic inequity attributable to this risk factor.

\section{References}

1. Fabelo Roche J, Lorenzo Vázquez EL, Iglesias More S, Alvarez Martinez E (2019) Impact of health warnings on cigarette packs on Cuban smokers. Health \& Society 9: 306-313.

2. Arredondo A, Recaman AL, Pinzon C, Azar A (2018) Financial consequences from smoking-related diseases in middle-income countries: Evidence and lessons from Mexico. Int J Health PlannMgmt 33(2): e454-e463.

3. Blanco, Adriana (2017) Ten years of the WHO Framework Convention on Tobacco Control: progress in the Americas. SaludPública de México 59(S1): 117-125.

4. Bardach AE, Caporale JE, Alcaraz A, Augustovski F, Huayanay Falconi L, et al. (2016) Burden of disease due to smoking and potential impact of the increase in cigarette prices in Peru. Revista Peruana de Medicina Experimental y Salud Pública 33(4): 651-661.

5. Guindon GE, Paraje GR, Chaloupka FJ (2016) The impact of prices and taxes on the consumption of tobacco products in Latin America and the Caribbean. Pan Am J Pub Health 40: 272-284.

6. Jiménez SY, Acuña MT (2016) Tobacco use in Costa Rica, relationship with multiple pathologies and importance of smoking cessation. RevistaPanamericana de SaludPública 40: 204-212.

7. García JC (2016) Smoking: a harmful scourge for humanity. Medical Archive Magazine of Camagüey 20(2): 114-117.

8. Sánchez González E, Fernández Hernández F (2019) The Smoking Fiscal Space in Cuba. Journal of Clinical and Medical Research 1(3).

9. Hernández FF, González SE (2019) Diploma Course: The Social Smoking Cost in the National Economy. A Necessary and Appliable Tool. HSOA Journal of Community Medicine and Public Health Care 6: 52.

10. Hernández FF, González SE (2019) Economic Inequity Attributable to Smoking Ratio's for the Public Health. Health Econ Outcome Res Open Access 4: 161.

11. Varian HR (2014) Intermediate Microeconomics with calculus: A modern approach: International student edition. New York.

12. Hernández FF, González SE (2017) Loss of productivity due to cigarette smoking during the working day. Cuben magazine of Health Work 18(3): 9-12.

13. Guerrero López CM, Reynales Shigematsu LM, Jiménez Ruiz JA, Karam Araujo R, Maldonado Cruz CA, et al. (2012) Costs for absenteeism attributable to tobacco consumption at the Mexican Institute of Social Security 
and in Mexico, 2006-2009. Public health México 54(3): 233-241.

14. Reynales LM (2012) Tobacco control, an essential strategy to reduce chronic non-communicable diseases. Public health México 54(3): 323-331.

15. Cardentey García J (2019) Smoking: a harmful scourge for humanity. AMC 20(2): 114-117.

16. Paredes Díaz R, Orraca Castillo O, Marimón Torres ER, Casanova Moreno MC, Véliz Martínez DM (2015) Influence of smoking and alcoholism on the health status of the population of Pinar del Rio. Rev CiencMéd 19(1): 46-55.

17. Fernández Hernández F, Sánchez González E (2017) Impact of smoking on the Cuban health budget 19972014. Revistadel Hospital Psiquiátrico de La Habana 14: 2.

18. Barrenechea G, Cali S (2016) Mortality attributable to smoking in Tucumán, Argentina 2001-2010. Medicina (B. Ai-res) 76(5): 287-293.

19. Guerrero Lópe CM, Muños Hernandez JA, Sáenz de Miera Juáre B, Reynales Shigematsu LM (2013) Tobacco use, mortality and fiscal policy in Mexico. public health Mexico. 55(S2): S276-S281.

20. Toledo Curbelo GJ (2008) Fundamentos de SaludPública. Segundaedición pp: 184-186.

21. (2015) Oficina Nacional de Estadísticas e Información (ONEI). AnuarioEstadístico de Cuba. Series Estadísticas. Salud y Asistencia Social.

22. Fernández Hernández F, Sánchez González E (2019) The economic burden of smoking. Spain.

23. Sánchez González E, Fernández Hernández F (2017) General economic characterization of cigarette consumption in Cuba from 2011 to 2013. Revistadel Hospital Psiquiátrico de La Habana 14(2).

24. Sánchez González E, Fernández Hernández F (2018) The relationship between tax policy and tobacco control in Cuba. CCM 22(2): 238-249.

25. Sánchez González E, Fernández Hernández F (2018) Social cost for absolute loss of labor productivity. Cuban magazine of health and work 19(1).018;19(1):33-39

26. Sánchez González E, Fernández Hernández F (2011) Opportunity cost for premature death of active Cuban smokers in 2011. pp: 26-31.
27. Sánchez González E, Fernández Hernández F (2020) Brief Appointments about Fiscal Policy for the Smoking Control. Journal of Clinical Research and Reports 2(5).

28. Fernández Hernández F, Sánchez González S (2020) Analytic validation of a formula estimating the smoking economic burden. MOJ Public Health 9(1): 5-7.

29. Sánchez González E, Fernández Hernández (2020) Rates to Measures the Social Inequity Attributable To Smoking. Journal of Clinical Research and Reports 2(4).

30. Fernández Hernández F, Sánchez González E (2020) The Social and Economic Inequity from Smoking in Cuba. Annals of Medical \& Surgical Case Report 2(2).

31. Sánchez González E, Fernández Hernández F (2020) The fiscal policy and the smoking control in Cuba. Journal of Clinical Research and Reports 2(4).

32. Fernandez Hernandez F, Sanchez González E (2020) The Smoking Economic Burden in the National Institute on Oncology and Radiology from Cuba. Journal of Medicine and Healthcare 2(2).

33. Sanchez Gonzalez E, Fernandez Hernández F (2017) The role of the tax authorities in tobacco control 21(3): 6267.

34. Sánchez González E, Fernández Hernández F (2019) A view for the morbidity attributable to smoking since the microeconomic. Trends in Research 2: 1-2.

35. Varona Pérez P, García Roche G, Willams Fogarty A, Britton J (2015) Lung cancer mortality and ischemic heart disease attributable to passive smoking in Cuba2011. Rev Cubana Hig Epidemiol 53(2).

36. Fernández Hernández F, Sánchez González E (2019) The socioeconomic inequity attributable to smoking in cuba. Journal of Medical Practice and Review 3(6): 559-562.

37. Fernández Hernández F, Sánchez González E (2019) Estimating the economic burden attributable to some risk factor. Journal of Clinical Investigation and Studies 2: $1-2$.

38. Sánchez González E, Fernández Hernández F (2016) Loss of work productivity attributable to smoking. RevistaCubana de Salud y Trabajo. 17(2): 57-60.

39. Fernández Hernández F, Sánchez González E (2018) Algorithm to calculate the smoking economical burden in active and passive smokers. MOJ Toxicol 4(6): 373375. 
Journal of Quality in Health care \& Economics

40. Fernández Hernández F, Sánchez González E (2020) Quantitative methods to explain the smoking economic impact. International Journal of Science and Academic Research 1(1): 1-2.

41. Fernández Hernández F, Sánchez González E (2017) Ca rgaepidemiológicavscargaeconómicadeltabaquismopor morbilidad. Rev Ciencias Médicas 21(2): 60-66.

42. Sánchez González E, Fernández Hernández F (2019) The social inequity across the smoking social costs. Ageing Science \& Mental Health Studies 3(5): 1-3.

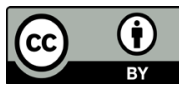

